\title{
Regulation of glucose metabolism via hepatic forkhead transcription factor 1 (FoxO1) by Morinda citrifolia (noni) in high-fat diet-induced obese mice
}

\author{
Pratibha V. Nerurkar ${ }^{1 *}$, Adrienne Nishioka ${ }^{1}$, Philip O. Eck ${ }^{1}$, Lisa M. Johns ${ }^{1} \dagger$, Esther Volper $^{2} \dagger$ \\ and Vivek R. Nerurkar ${ }^{2}$ \\ ${ }^{1}$ Laboratory of Metabolic Disorders and Alternative Medicine, Department of Molecular Biosciences and Bioengineering \\ (MBBE), College of Tropical Agriculture and Human Resources (CTAHR), University of Hawaii at Manoa, Honolulu, \\ HI 96822, USA \\ ${ }^{2}$ Retrovirology Research Laboratory, Department of Tropical Medicine, Medical Microbiology and Pharmacology, \\ John A. Burns School of Medicine, University of Hawaii at Manoa, Honolulu, HI 96813, USA
}

(Submitted 4 February 2011 - Final revision received 14 September 2011 - Accepted 14 September 2011 - First published online 20 October 2011)

\begin{abstract}
Renewed interest in alternative medicine among diabetic individuals prompted us to investigate anti-diabetic effects of Morinda citrifolia (noni) in high-fat diet (HFD)-fed mice. Type 2 diabetes is associated with increased glucose production due to the inability of insulin to suppress hepatic gluconeogenesis and promote glycolysis. Insulin inhibits gluconeogenesis by modulating transcription factors such as forkhead box O (FoxO1). Based on microarray analysis data, we tested the hypothesis that fermented noni fruit juice (fNJ) improves glucose metabolism via FoxO1 phosphorylation. C57BL/6 male mice were fed a HFD and fNJ for 12 weeks. Body weights and food intake were monitored daily. FoxO1 expression was analysed by real-time PCR and Western blotting. Specificity of fNJ-associated FoxO1 regulation of gluconeogenesis was confirmed by small interfering RNA (siRNA) studies using human hepatoma cells, HepG2. Supplementation with fNJ inhibited weight gain and improved glucose and insulin tolerance and fasting glucose in HFD-fed mice. Hypoglycaemic properties of fNJ were associated with the inhibition of hepatic FoxO1 mRNA expression, with a concomitant increase in FoxO1 phosphorylation and nuclear expulsion of the proteins. Gluconeogenic genes, phosphoenolpyruvate C kinase (PEPCK) and glucose-6-phosphatase (G6P), were significantly inhibited in mice fed a HFD + fNJ. HepG2 cells demonstrated more than $80 \%$ inhibition of PEPCK and G6P mRNA expression in cells treated with FoxO1 siRNA and fNJ. These data suggest that fNJ improves glucose metabolism via FoxO1 regulation in HFD-fed mice.
\end{abstract}

Key words: Morinda citrifolia: Noni: FoxO1: Diabetes: Obesity

Type 2 diabetes is escalating worldwide and is estimated to affect 23.6 million people or $7 \cdot 8 \%$ of the US population. About 800000 new diabetes cases are diagnosed each year, and diabetes is the sixth leading cause of death in the USA. According to the National Diabetes Statistics of 2007, the average medical expenditure for diabetics was 2.3 times higher than that compared with non-diabetics and estimated at a total of $\$ 174$ billion in direct and indirect costs of health care expenditures (http://www.diabetes.org/diabetesstatistics.jsp). The prevention and treatment cost for diabetes is estimated to exceed US \$302 billion by 2025 . Considering the heterogeneity of diabetes and the limitations of current therapies, such as various side effects as well as high secondary failure rates, there is an urgent need to explore new antidiabetic agents. Furthermore, there is a growing and renewed interest in effective but low-cost alternative therapies with minimum side effects.

Morinda citrifolia L. (Rubiaceace), commonly known as 'noni' is native to Polynesia and widely cultivated in tropical areas of the South Pacific. In the USA, noni is grown in Hawaii and Florida. It is also native to Australia, Malaysia, the West Indies, India, Vietnam, the Philippines, Taiwan and other tropical parts of the world. Claims of its healing powers' have fuelled much of the commercial interest in

Abbreviations: fNJ, fermented noni juice; FoxO, forkhead box O; G6P, glucose-6-phosphatase; GCK, glucokinase; HFD, high-fat diet; HOMA-IR, homeostasis model assessment-insulin resistance; NJ, noni juice; PEPCK, phosphoenolpyruvate C kinase; siRNA, small interfering RNA; UHM, University of Hawaii at Manoa.

*Corresponding author: Dr P. V. Nerurkar, fax +1808956 3542, email pratibha@hawaii.edu

† L. M. J. and E. V. have contributed equally to the manuscript. 
noni and promoting a worldwide market for noni-based dietary supplements including fruit juice. Pacific Islanders and Native Hawaiians consume noni juice prepared by fermenting the fruits ${ }^{(1)}$. Traditionally, the stem, bark, root and leaves of noni have been used for centuries to treat diabetes, hypertension, cancer and $\mathrm{CVD}^{(1-3)}$. Earlier scientific studies have investigated the anticancer, antioxidant and immunomodulatory properties of noni ${ }^{(4-9)}$. Similarly, Zhang et al. ${ }^{(9)}$ demonstrated that fermented noni fruit exudates or juice significantly reduced tumour burden in animals. Recent studies have demonstrated that root extracts of Morinda officinalis and M. citrifolia lowered plasma glucose in streptozotocininduced diabetic rats and mice, respectively ${ }^{(10-12)}$, while treatment with Tahitian noni fruit juice (NJ) for 4 weeks reduced blood glucose in alloxan-induced diabetic rats ${ }^{(13)}$. However, the anti-diabetic mechanisms of noni remain unknown.

Obesity-associated insulin resistance is an important aetiological factor of type 2 diabetes and is associated with increased glucose production due to the inability of insulin to suppress hepatic gluconeogenesis and promote glycolysis ${ }^{(14)}$. Insulin suppresses hepatic gluconeogenesis via activation of the Akt/phosphatidylinositol-3-kinase pathway and subsequent phosphorylation of forkhead box O (FoxO) transcription factors $^{(14-16)}$. FoxO proteins are a family of transcription factors consisting of FoxO1, FoxO3a, FoxO4 and FoxO6, involved in several signalling cascades that regulate cell-cycle progression, cell death, DNA repair, protection against oxidative stress, glucose and lipid metabolism, and longevity ${ }^{(17)}$. FoxO1, along with the PPAR $\gamma$-coactivator $1 \alpha$, stimulates glucose production by stimulating gluconeogenic enzymes, phosphoenolpyruvate carboxy kinase (PEPCK) and glucose6-phosphatase, catalytic (G6P), via the cyclic AMP/Creb pathway ${ }^{(14)}$. Under conditions of high circulating plasma glucose levels, insulin-induced phosphorylation of FoxO1 via Akt/ phosphatidylinositol-3-kinase activation results in the nuclear expulsion of FoxO and the inhibition of PEPCK and G6P ${ }^{(18)}$, as well as the increase in genes regulating glycolysis such as glucokinase $(\mathrm{GCK})^{(16)}$. A recent study by Horsfall et al. ${ }^{(13)}$ indicated that fermented noni juice (fNJ) synergistically augmented insulin action in diabetic rats by lowering fasting glucose. Therefore, the aim of the present study was to investigate the molecular mechanism associated with insulin mimetic effects of $M$. citrifolia $\mathrm{L}$. on hepatic gluconeogenic genes such as PEPCK and G6P and glycolytic genes such as $G C K$, and FOXO phosphorylation.

\section{Materials and methods}

\section{Preparation of fermented noni fruit juice}

$\mathrm{NJ}$ is commercially available as pure noni fruit juice. Moreover, NJ mixed with other fruit juices, such as apple, cranberry and/ or grapes, is also popular. We tested the hypoglycaemic effects of $\mathrm{fNJ}$ in mice fed a high-fat diet (HFD). Ripened fruits of $M$. citrifolia L. were obtained from local plants in Honolulu, Hawaii, located near the University of Hawaii at Manoa (UHM) and placed in a closed glass jar in partial light at room temperature $\left(20-25^{\circ} \mathrm{C}\right)$. All fruits were obtained from the same area, in fact the same plant, and were of the same age based on the degree of ripeness. After 2 weeks, the fermented fruits along with the juices and pulp were collected and strained through cheese cloth ${ }^{(9)}$. The juice was stored at $0-4{ }^{\circ} \mathrm{C}$ until analysis. Fruits were identified by Dr Will McClatchey, ethnobotanist, at the University of Hawaii, and voucher specimens were deposited at the official herbaria, UHM herbarium (HAW), and labelled as NerurkarNoni0001 and NerurkarNoni0002. Chemical analysis was conducted at cost by outsourcing to analytical laboratories in Honolulu, Hawaii. Physical properties and mineral contents of fNJ were analysed at the Agricultural Diagnostic Service Center, UHM, while scopoletin content was analysed at the Analytical Laboratory, Cancer Research Center of Hawaii, UHM using standard liquid chromatography-MS techniques (Table 1).

\section{Experimental design}

Male C57BL/6 mice, 4-6 weeks old, were purchased from Jackson Laboratories (Ann Arbor, MI, USA) and randomised into four groups of six animals each: control; HFD; control $+\mathrm{fNJ} ; \mathrm{HFD}+\mathrm{fNJ}$. Control rodent chow contained $11 \% \mathrm{~kJ}$ fat, $16 \% \mathrm{~kJ}$ protein and $73 \% \mathrm{~kJ}$ carbohydrate $(17.02 \mathrm{~kJ} / \mathrm{g}$, \#D12328; Research Diets, New Brunswick, NJ, USA), whereas HFD chow contained $58 \% \mathrm{~kJ}$ fat, $16 \% \mathrm{~kJ}$ protein and $26 \% \mathrm{~kJ}$ carbohydrate $\left(131 \cdot 2 \mathrm{~kJ} / \mathrm{g}\right.$, \#D12331; Research Diets) ${ }^{(19)}$. Nutrient contents of the two diets have been published earlier ${ }^{(19)}$. fNJ was fed orally, twice per $d$ at physiologically relevant human consumption levels of $1.5 \mu \mathrm{l} / \mathrm{g}$ body weight (v/w), for 12 weeks. For adults, the suggested dose for commercial noni juice is about 2 ounces twice per d (a total of 4 ounces or $118 \mathrm{ml}$ ). Assuming an average of $70 \mathrm{~kg}$ adult, the dosage

Table 1. Physical properties and mineral contents of fermented noni juice (fNJ)*

(Mean values and standard deviations)

\begin{tabular}{lcc}
\hline & \multicolumn{2}{c}{$\mathrm{fNJ}(n \mathrm{n})$} \\
\cline { 2 - 3 } Analysis & Mean & SD \\
\hline DM (\%) & 7.0 & 0.06 \\
Ash (\%) & 0.8 & 0.01 \\
Crude protein (\% kJ) & 35.6 & 0.2 \\
Crude fat (\% kJ) & 1.86 & 0.3 \\
Neutral fibre (\% kJ) & 43.5 & 8.4 \\
Acid fibre (\% kJ) & 56.1 & 5.4 \\
Carbohydrate (\% kJ) & 8.0 & 0.92 \\
Minerals & & \\
P (\%) & 0.12 & 0.002 \\
K (\%) & 4.3 & 0.09 \\
Ca (\%) & 0.36 & 0.01 \\
Mg (\%) & 0.33 & 0.002 \\
Na (\%) & 0.33 & 0.01 \\
B (ppm) & 25.5 & 0.7 \\
Cu (ppm) & 1.0 & 0.0 \\
Fe (ppm) & 52.5 & 5.0 \\
Mn (ppm) & 13.0 & 0.0 \\
Zn ( $\mu \mathrm{g} / \mathrm{g})$ & 14.0 & 5.7 \\
Scopoletin $(\mu \mathrm{g} / \mathrm{ml})$ & 85.0 & 12.6 \\
\hline
\end{tabular}

ppm, Parts per million.

${ }^{\star}$ Values are based on the analysis of $50 \mathrm{ml}$ of $\mathrm{fNJ}$ per replicate. 
is about $1.68 \mu \mathrm{l} / \mathrm{g}$ body weight. However, future studies are required to optimise the exact dosage in $\mathrm{C} 57 \mathrm{BL} / 6$ mice. $\mathrm{fNJ}$ was fed to the mice orally through a pipette and the tip was held in the mouth, until all the fNJ was swallowed. Control mice were fed an equivalent amount of water using a pipette. All procedures were conducted in accordance with guidelines established by the National Institutes of Health and the University of Hawaii Institutional Animal Care and Use Committee. Animals were housed individually and allowed to eat and drink ad libitum for 12 weeks. Body weights, food and water intake were measured daily. At the end of the study, after an overnight fast, mice in each group were anaesthetised by isofluorane, followed by blood drawn through cardiac puncture. All tissues were snap-frozen in liquid $\mathrm{N}_{2}$ and stored at $-80^{\circ} \mathrm{C}$ until further analysis.

\section{Analytical procedures}

For plasma preparation, whole blood was collected in heparinised tubes. Liver function tests were analysed by measuring alanine aminotransferase, aspartate aminotransaminase (Biotron Diagnostics USA, Inc., Hemet, CA, USA) and lactate dehydrogenase (Bioassays Systems, Hayward, CA, USA) ${ }^{(19)}$.

Glucose and insulin tolerance tests were conducted after a $4 \mathrm{~h}$ fast, as described previously ${ }^{(19)}$. In brief, tolerance tests were conducted after an intraperitoneal injection of either $50 \%$ dextrose at $1.5 \mathrm{mg} / \mathrm{g}$ body weight (NDC 57319-071-07; IVX Animal Health, Inc., St Joseph, MO, USA) or human insulin at $0.5 \mathrm{U} / \mathrm{kg}(3.0 \mathrm{nmol} / \mathrm{l}$ per $\mathrm{kg})$ body weight (Novolin R, Human, U-100, catalogue no. 183311; Novo Nordisk, Inc., Princeton, NJ, USA). Tail vein blood was used to determine blood glucose levels at 0, 30, 60 and $120 \mathrm{~min}$ with a One Touch Ultra $^{\mathrm{TM}}$ glucometer (Lifescan, Philadelphia, PA, USA).

\section{RNA extraction}

In brief, a PRO 200 Laboratory Homogenizer (Pro Scientific, Oxford, CT, USA), was used to homogenise 30-40 $\mathrm{mg}$ of liver, followed by the QIAshredder (catalogue no. 79656; Qiagen, Inc., Valencia, CA, USA), and RNA was extracted using the RNeasy Mini Kit (catalogue no. 74104; Qiagen, Inc.), according to the manufacturers' protocol. The quality of RNA was tested using the Agilent bioanalyser at the Greenwood Molecular Biology Facility, Pacific Biosciences Research Center, UHM. The 18S:28S ratios of all samples were in the range of $1 \cdot 8-2 \cdot 0$.

\section{Genome-wide microarray analysis}

Transcriptional profiling of mouse liver was performed using the Affymetrix GeneChip Mouse Genome 430 2.0 Array (part no. 900497; Affymetrix, Inc., Santa Clara, CA, USA), according to the standard GeneChip eukaryotic target labelling protocol (Affymetrix, Inc.) at the Greenwood Molecular Biology Facility, Pacific Biosciences Research Center, University of Hawaii. All subsequent manipulations, including labelling and hybridisation, were performed independently for each sample as published ${ }^{(20)}$. Briefly, $10 \mu \mathrm{g}$ of total cellular
RNA per sample were used to synthesise double-stranded complementary DNA, which then was transcribed in vitro in the presence of biotinylated dNTP (Enzo Diagnostics, Farmingdale, NY, USA). Successful labelling of all the samples was tested by test array hybridisations, using the Affymetrix GeneChip Test3 Array (part no. 900341; Affymetrix, Inc.), to ensure quality of the biotinylated target. Appropriate internal controls were added to the hybridisation cocktail. Gene chip arrays were scanned at $570 \mathrm{~nm}$ with a gene array scanner and analysed with Gene Chip Operating Software version 1.4 (Affymetrix, Inc.). The method of normalisation used was a scaling algorithm, which involves multiplying the mean intensity of each chip (not including the upper and lower $2 \%$ ) by a factor, which changes the mean intensity to 500 for every chip. By scaling each chip, a direct comparison could be made between all the chips. For a given gene transcript in any chip-to-chip comparison, Gene Chip Operating Software generates a 'change call' parameter 'increase' or 'decrease' based on a consideration of signal specificity as well as intensity. The 'change call' is based on an evaluation of the intensities of the signals generated from each gene transcript on one chip relative to the corresponding signal intensities on the other chip. The data were filtered using Genespring 9.0 software, based on both 'detection call' (presence or absence) and 'signal log ratio' (1.5-fold change) in any of the comparisons between the control and various treatment groups. In the case of the Affymetrix 'detection call' algorithm, genes that were 'absent' in all samples were filtered out. Genes had to be detected or 'present' in at least one out of the four treatment groups. Additional filter was based on the 'signal log ratio', which is the log base 1.5 of the fold change. Relative changes equal to or greater than 1.5 -fold levels of expression were considered significant.

\section{Validation of selected genes by real-time RT-PCR}

To confirm changes in the expression of selected genes, RNA samples from all groups of animals, including those analysed by microarray, were assayed by real-time PCR using SYBR Green (Bio-Rad iCycler, Hercules, CA, USA). In brief, $1 \mu \mathrm{g}$ of total RNA was used for complementary DNA synthesis (iScript complementary DNA Synthesis Kit; Bio-Rad) and real-time RT-PCR was conducted using $2 \mu$ l of diluted complementary DNA (1:3) in duplicate, with both internal and no template controls. Primer sequences used for amplification of specific genes were designed using Beacon Designer 2.0 primer design software (PREMIER Biosoft International, Palo Alto, CA, USA; Table 2). The housekeeping gene GAPDH was used as an internal control for normalisation in parallel with each gene of interest. PCR cycling conditions were $95^{\circ} \mathrm{C}$ for $5 \mathrm{~min}$, forty-five cycles of $95^{\circ} \mathrm{C}$ for $10 \mathrm{~s}, 54^{\circ} \mathrm{C}$ for $45 \mathrm{~s}$, and the melt curve starting from $55^{\circ} \mathrm{C}$ of eighty cycles increasing $0.5^{\circ} \mathrm{C}$ every $10 \mathrm{~s}$. Each reaction was performed at least twice in duplicate, to verify reproducibility. PCR product intensity data were normalised relative to GAPDH, and relative fold change was obtained using the $\Delta \Delta C_{\mathrm{t}}$ equation, which was calculated by Bio-Rad iQ5 software (Bio-Rad, Hercules, CA, USA). 
Table 2. Mouse and human primer sequences for real-time RT-PCR

\begin{tabular}{|c|c|c|}
\hline Target gene (GenBank accession no.) & Primer sequence & Amplicon size (bp) \\
\hline mFoxO1 (Al462296) & $\begin{array}{l}\text { Forward 5'-ACGGGCTGTCTGTCTGTC- } 3^{\prime} \\
\text { Reverse 5'-TAAGTGAAGTTTCTCTGTGGTTTC- } 3^{\prime}\end{array}$ & 116 \\
\hline$m G 6 P c$ (NM_008061) & $\begin{array}{l}\text { Forward 5'-GGTTCATCCTTGTGTCTGTG-3' } \\
\text { Reverse 5'-GCTGTAGTAGTCGGTGTCC-3' }\end{array}$ & 200 \\
\hline mGCK (L38990) & $\begin{array}{l}\text { Forward 5'-GTAAGGCACGAAGACATAGAC-3' } \\
\text { Reverse 5'-TCCCACGATGTTGTTCCC-3' }\end{array}$ & 90 \\
\hline mPEPCK2 (NM_028994) & $\begin{array}{l}\text { Forward 5'-AAATGTGTGAGTGTTGGAAGG-3' } \\
\text { Reverse 5'-AGACCGATTAGAAGGAAGCC-3' }\end{array}$ & 126 \\
\hline mGAPDH (NM_001001303) & $\begin{array}{l}\text { Forward 5'-TCAACGGCACAGTCAAGG-3' } \\
\text { Reverse 5'-ACTCCACGACATACTCAG-3' }\end{array}$ & 126 \\
\hline hFoxO1 (NM_002015) & $\begin{array}{l}\text { Hs_FOXO1_1_SG; QuantiTect Primer Assay; } \\
\text { Qiagen, Inc., Valencia, CA, USA }\end{array}$ & 98 \\
\hline hPEPCK2 (NM_004563) & $\begin{array}{l}\text { Forward 5'-AACCAGGATCTGCCCAAAG-3' } \\
\text { Reverse 5'-TGCTATGTCCTCTTGCTAGAC-3' }\end{array}$ & 102 \\
\hline$h \beta$-Actin (NM_001101) & $\begin{array}{l}\text { Forward 5'-CATGGAGTCCTGTGGCATC-3' } \\
\text { Reverse 5'-AGCACTGTGTTGGCGTAC-3' }\end{array}$ & 93 \\
\hline
\end{tabular}

$\mathrm{m}$, Mouse; h, human.

\section{Analysis of hepatic forkhead box O phosphorylation by} Western blotting

Whole cell extracts were prepared from frozen livers, as published earlier ${ }^{(21)}$. In brief, proteins were extracted with ice-cold buffer containing $10 \mathrm{~mm}$-Tris-HCl ( $\mathrm{pH} \mathrm{7.4),}$ $150 \mathrm{~mm}-\mathrm{NaCl}, 1 \mathrm{~mm}-\mathrm{EDTA}, 1 \mathrm{~mm}$-ethylene glycol tetraacetic acid, $100 \mathrm{~mm}-\mathrm{NaF}, 150 \mathrm{~mm}$-sodium pyrophosphate, $2 \mathrm{~mm}-$ sodium orthovanadate, $2 \mathrm{~mm}$-phenylmethylsulphonyl fluoride and protease inhibitor (Roche Diagnostics Corporation, Indianapolis, IN, USA). Homogenates were centrifuged at $12000 \mathrm{rpm}$ at $4^{\circ} \mathrm{C}$ for $20 \mathrm{~min}$ and supernatants were stored at $-80^{\circ} \mathrm{C}$ until further analysis. Protein concentrations were determined using the Bradford protein assay reagent (Bio-Rad Laboratories), according to the manufacturer's instructions. Briefly, cytoplasmic and nuclear proteins (100 mg and $50 \mathrm{mg}$, respectively) were separated on $4-15 \%$ gradient polyacrylamide gels (Bio-Rad Laboratories) and transferred to nitrocellulose membrane. The membranes were blocked in $0.5 \%$ bovine serum albumin prepared in Tween/Tris-buffered saline and incubated overnight in goat phosphorylated Forkhead transcription factor (FKHR) (T-24) primary antibody (Santa Cruz Biotechnology, Inc., Santa Cruz, CA, USA) at room temperature. After washing, blots were probed with donkey anti-goat IgG horseradish peroxidase conjugate secondary antibody (Santa Cruz Biotechnology, Inc.). Blots were stripped using ReBlot Plus mild stripping solution (Millipore, Billerica, MA, USA) and probed for total FoxO with rabbit polyclonal FKHR (H-128; Santa Cruz Biotechnology, Inc.) and later with $\beta$-actin using monoclonal $\beta$-actin primary antibody (Sigma Chemicals, St Louis, MO, USA). All aforementioned primary and secondary antibodies were used at 1:3333 and 1:5000 dilutions, respectively. Proteins were visualised using a commercially available electrochemiluminescence kit (Novex ${ }^{\circledR}$ ECL Chemiluminescent Substrate; Invitrogen Corporation, Carlsbad, CA, USA). Protein bands were scanned and intensities were analysed using 'UN-SCAN-IT gel' analysis software (Silk Scientific, Inc., Orem, UT, USA).

\section{HepG2 cell culture}

Human hepatoma cells, HepG2, were obtained from the ATCC (Manassas, VA, USA) and maintained in Eagle's minimum essential medium supplemented with 10\% heat-inactivated fetal bovine serum from SAFC Biosciences (Lenexa, KS, USA) and $1 \%$ penicillin-streptomycin from Sigma-Aldrich Company. Cells were used between passages 9 and 10 and used at 80-90\% confluency.

\section{Forkhead box O ELISA}

For phosphorylation studies, HepG2 cells were seeded in ninety-six-well plates at a density of $5 \times 10^{4}$ cells/well in $200 \mu \mathrm{l}$ media. At $72 \mathrm{~h}$ after plating, cells were serum-starved for $16 \mathrm{~h}$, followed by treatment with and without 1.5 and $3 \%$ $\mathrm{fNJ}$ in complete medium for $24 \mathrm{~h}$. Doses were chosen based on our initial toxicity studies with varying concentrations of $\mathrm{fNJ}(\mathrm{v} / \mathrm{v})$ in serum-starved cells (data not shown). Cells were treated with and without $100 \mathrm{~nm}$-bovine pancreas insulin (Sigma-Aldrich Company) for the last $30 \mathrm{~min}$ before the assay. Cells were washed twice with serum-free medium and fixed in $4 \%$ formaldehyde in PBS, followed by incubation in quenching buffer containing $1 \% \mathrm{H}_{2} \mathrm{O}_{2}$ and $0 \cdot 1 \%$ sodium azide in PBS. Cells were then blocked with a $5 \%$ non-fat milk in buffer containing $10 \mathrm{~mm}-\mathrm{Na}_{2} \mathrm{HPO}_{4}, 1.8 \mathrm{~mm}-\mathrm{KH}_{2} \mathrm{PO}_{4}$, $2.7 \mathrm{~mm}-\mathrm{KCl}, 0 \cdot 15 \mathrm{M}-\mathrm{NaCl}$ and $0 \cdot 1 \%$ Triton X-100. Total and phosphorylated FoxO were detected using the FACE $^{\mathrm{TM}}$ FKHR ELISA kit (Active Motif, Carlsbad, CA, USA), according to the manufacturer's protocol. The ELISA kit provides a simple and sensitive method for detecting protein phosphorylation directly in the cell without Western blotting. In brief, blocked cells were incubated overnight at room temperature with phosphorylated or total FoxO1 primary antibody, followed by $1 \mathrm{~h}$ incubation with horseradish peroxidase-conjugated secondary antibody. After the addition of developing and stop solutions, absorbance was measured at $450 \mathrm{~nm}$ with the Wallac Victor ${ }^{2} 1420$ Multilabel Counter (PerkinElmer Life Sciences, Boston, MA, USA). Background absorbance was 
measured using a reference wavelength of $655 \mathrm{~nm}$. Values were normalised to the cell number measured by staining the cells with Crystal Violet dye provided in the kit. After $30 \mathrm{~min}$, cells were solubilised with $1 \%$ SDS for $1 \mathrm{~h}$ and absorbance was read at $590 \mathrm{~nm}$.

\section{Small-interference RNA for forkhead box 01}

For transfection studies, HepG2 cells were plated in clear six-well plates at a density of $3.3 \times 10^{5}$ cells/well. After $24 \mathrm{~h}$ plating, cells were transiently transfected with a mixture of DharmaFECT 4 reagent and either FoxO1 small interfering RNA (siRNA) or non-target siRNA (Dharmacon, Inc., Lafeyette, CO, USA) using serum-free, antibiotic-free, Eagle's minimum essential medium (ATCC) to a final concentration of $100 \mathrm{~nm}$, in accordance with the manufacturers' instructions. After $16 \mathrm{~h}$, serum was added to the cells to a final concentration of $10 \%$. Cells were transfected for a total of $48 \mathrm{~h}$, after which they were washed and treated with varying concentrations of fNJ for $1 \mathrm{~h}$. Efficiency of FoxO1 knockdown and mRNA expressions of PEPCK, G6P and GCK were determined by quantitative RT-PCR. In brief, total RNA was extracted from HepG2 cells using Tri Reagent (Sigma-Aldrich Company), according to the manufacturer's instructions. DNA was then digested using the commercial DNA-free kit (Ambion, Austin, TX, USA), according to the manufacturer's instructions. All RNA samples had 260:280 ratios between 1.8 and 2.0.

\section{Statistical analysis}

Homeostasis model assessment (HOMA) was used to calculate relative insulin resistance $\left(G_{0} \times I_{0} / 22 \cdot 5\right)$, where $G_{0}$ is the fasting blood glucose $(\mathrm{mmol} / \mathrm{l})$ and $I_{0}$ is the fasting plasma insulin $(\mu \mathrm{U} / 1)$. All statistical calculations were performed using GraphPad Prism, Prism 5 for Windows, version 5.01 (GraphPad Software, Inc., San Diego, CA, USA). A one-way ANOVA model was used to compare means between the four animal groups (control, HFD, control $+\mathrm{fNJ}$ and HFD $+\mathrm{fNJ}$ ). For repeated assays of plasma concentrations of various blood analytes, a repeated-measure ANOVA was used to compare means. Each sample was analysed twice in duplicate. Post hoc pairwise multiple comparisons were evaluated using Tukey's multiple comparison test, after ANOVA. All $P$ values were based on two-sample tests. Results were considered significant at $P<0 \cdot 05$.

\section{Results}

Fermented noni juice reduces body weights and improves glucose tolerance in mice fed a high-fat diet

Control mice fed with fNJ did not have any significant effect on the daily intake and total energy of food consumed when compared with mice fed the control diet (Table 3). Both daily and total food intake were comparable in mice fed the HFD and HFD + fNJ, but were lower when compared with control diet-fed mice and control diet + fNJ-fed mice $(P<0.03$; Table 3). Although there were no differences in initial body weights among all groups of mice, at the end of 12 weeks, the final body weights of HFD-fed mice were 23 and $28 \%$ greater than control diet-fed mice and control diet + fNJ-fed mice, respectively (Table 3 ). fNJ significantly lowered $(P<0.05)$ the final body weights by $10 \%$ among mice fed a HFD + fNJ, compared with HFD-fed mice, but was significantly higher $(P<0.05)$ by $12 \%$ than mice fed a control diet (Table 3). Overall, the total weight gain in HFD-fed mice, over a period of 12 weeks, was significantly higher (164\%) $(P<0.05)$ than control diet-fed mice (Table 3). Similarly, the total weight gain in mice fed with the HFD + fNJ was significantly higher than control diet-fed mice (91\%) $(P<0.05)$, but $27 \%$ lower than HFD-fed mice $(P<0.05)$. Feeding of the control diet $+\mathrm{fNJ}$ had no significant effect on body weights when compared with control diet-fed mice, but were lower than those of HFD- and HFD + fNJfed mice (Table 3).

Table 3. Metabolic parameters in C57BL/6 female mice fed a high-fat diet (HFD) and fermented noni juice (fNJ) (Mean values and standard deviations)

\begin{tabular}{|c|c|c|c|c|c|c|c|c|}
\hline \multirow[b]{2}{*}{ Variables } & \multicolumn{2}{|c|}{ Control } & \multicolumn{2}{|c|}{ Control $+\mathrm{fNJ}$} & \multicolumn{2}{|c|}{ HFD } & \multicolumn{2}{|c|}{$\mathrm{HFD}+\mathrm{fNJ}$} \\
\hline & Mean & SD & Mean & SD & Mean & SD & Mean & SD \\
\hline Daily food intake $(\mathrm{kJ} / \mathrm{d}, n 7)$ & $58 \cdot 2^{\mathrm{a}}$ & 7.5 & $56 \cdot 5^{\mathrm{a}}$ & 5.5 & $51.9^{\mathrm{b}}$ & $4 \cdot 2$ & $49 \cdot 4^{\mathrm{b}}$ & $2 \cdot 9$ \\
\hline Total food intake $(\mathrm{kJ}, n 7)^{*}$ & $5075 \cdot 2^{\mathrm{a}}$ & $506 \cdot 3$ & $4941 \cdot 2^{\mathrm{a}}$ & $230 \cdot 1$ & $3673 \cdot 6^{b}$ & 351.5 & $3569 \cdot 0^{\mathrm{b}}$ & $200 \cdot 8$ \\
\hline Initial body weight $(\mathrm{g}, n 7)$ & $22 \cdot 6^{\mathrm{a}}$ & 1.0 & $22 \cdot 5^{\mathrm{a}}$ & $1 \cdot 2$ & $23 \cdot 2^{\mathrm{a}}$ & $1 \cdot 7$ & $22 \cdot 6^{\mathrm{a}}$ & 1.8 \\
\hline Final body weight $(\mathrm{g}, n 7)$ & $26 \cdot 0^{\mathrm{a}}$ & 1.9 & $24 \cdot 9^{\mathrm{a}}$ & 1.5 & $32 \cdot 2^{\mathrm{b}}$ & 2.09 & $29 \cdot 1^{\mathrm{a}}$ & $2 \cdot 9$ \\
\hline Total weight gain $(\mathrm{g}, n 7)$ & $3.4^{\mathrm{a}}$ & 1.2 & $2 \cdot 4^{\mathrm{a}}$ & 0.5 & $9.0^{\mathrm{b}}$ & $2 \cdot 1$ & $6 \cdot 5^{\mathrm{c}}$ & 1.9 \\
\hline Fasting glucose $(\mathrm{mg} / \mathrm{l}, n \mathrm{7})$ & $860^{\mathrm{a}}$ & 103 & $893^{a}$ & 138 & $1437^{\mathrm{b}}$ & 103 & $934^{\mathrm{a}}$ & 153 \\
\hline Fasting insulin $(\mathrm{ng} / \mathrm{ml})$ & $0.72^{\mathrm{a}}$ & 0.06 & $0.72^{\mathrm{a}}$ & 0.04 & $1.34^{\mathrm{b}}$ & 0.06 & $1.05^{\mathrm{a}}$ & 0.06 \\
\hline HOMA-IR $(n 7)$ & $3 \cdot 8^{\mathrm{a}}$ & 0.4 & $3.9^{\mathrm{a}}$ & 0.6 & $11.9^{\mathrm{b}}$ & 5.4 & $6 \cdot 0^{\mathrm{C}}$ & $1 \cdot 1$ \\
\hline GTT (AUC, $n 7$ ) & $32081^{a}$ & 4613 & $31496^{a}$ & 5531 & $40869^{b}$ & 3810 & $30375^{a}$ & 1767 \\
\hline ITT (AUC, $n 7$ ) & $10990^{a}$ & 2643 & $10655^{a}$ & 1159 & $14848^{\mathrm{b}}$ & 895 & $11565^{a}$ & 1261 \\
\hline Serum AST (Ú/l, $n 7)$ & $6 \cdot 3^{\mathrm{a}}$ & $1 \cdot 2$ & $5 \cdot 8^{\mathrm{a}}$ & 1.5 & $58 \cdot 0^{\mathrm{b}}$ & $16 \cdot 1$ & $28 \cdot 3^{\mathrm{c}}$ & $7 \cdot 7$ \\
\hline Serum ALT (U/I, n 7) & $9 \cdot 1^{a}$ & $2 \cdot 8$ & $8 \cdot 5^{\mathrm{a}}$ & $2 \cdot 4$ & $37 \cdot 2^{\mathrm{b}}$ & 6.6 & $13.7^{\mathrm{c}}$ & 2.6 \\
\hline Serum LDH (U/l, $n 7)$ & $89 \cdot 3^{\mathrm{a}}$ & $10 \cdot 06$ & $95 \cdot 5^{\mathrm{a}}$ & 11.7 & $224.4^{b}$ & $29 \cdot 1$ & $112 \cdot 6^{\mathrm{a}}$ & $15 \cdot 3$ \\
\hline
\end{tabular}

HOMA-IR, homeostasis model assessment-insulin resistance; GTT, glucose tolerance test; AUC, area under the curve; ITT, insulin tolerance test; AST, aspartate aminotransaminase; ALT, alanine aminotransferase; $\mathrm{LDH}$, lactate dehydrogenase.

a,b,c Mean values with unlike superscript letters were significantly different $(P<0.05)$.

* Total food intake per mouse for 12 weeks. 

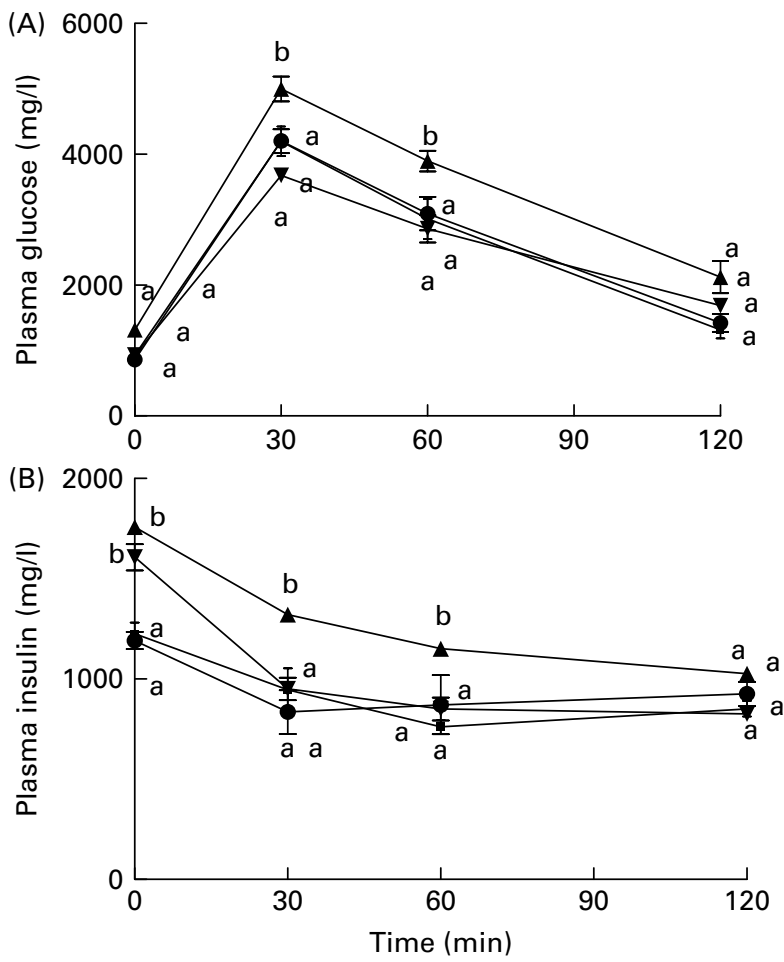

Fig. 1. Effects of fermented noni juice ( $\mathrm{fNJ}$ ) on glucose and insulin tolerance in high-fat diet (HFD)-fed mice. fNJ improves (A) glucose tolerance and (B) insulin tolerance in mice fed a control rodent chow (Con, - - ), Con $+\mathrm{fNJ}$ $(\rightarrow)$, HFD $(-\boldsymbol{\sim})$ and HFD + fNJ $(-\boldsymbol{\sim})$ for 12 weeks. Values are means, with standard errors represented by vertical bars $(n 6)$. ${ }^{\mathrm{a}, \mathrm{b}}$ Mean values of HFD-fed mice with unlike letters were significantly different from those of the control, fNJ and HFD + fNJ groups $(P<0.05)$.

The baseline fasting glucose did not differ between the groups (data not shown). However, by 12 weeks, fasting glucose levels among HFD-fed mice were significantly higher by 67 and $61 \%(P<0.05)$ when compared with control diet-fed mice and control diet + fNJ-fed mice, respectively (Table 3 ). fNJ did not affect blood glucose levels in control diet-fed mice, but significantly lowered $(P<0.05)$ glucose levels by $35 \%$ in mice fed the HFD $+\mathrm{fNJ}$ when compared with mice fed only the HFD (Table 3). Similarly, insulin levels were significantly elevated in mice fed the HFD compared with control diet-fed mice and control diet + fNJ-fed mice. Mice fed the HFD + fNJ demonstrated lower plasma insulin compared with all the other groups (Table 3). Compared with HFD-fed mice, improvement in whole body glucose metabolism, among mice fed the HFD with NJ was apparent by improved fasting glucose and HOMA index (Table 3). HOMA-IR was significantly higher $(P<0.05)$ in HFD-fed mice when compared with control diet-fed mice. Mice fed the HFD + fNJ demonstrated significantly lower HOMA-IR $(P<0.05)$ when compared with HFD-fed mice, but were higher compared with control diet-fed mice (Table 3). The area under the curve for both glucose and insulin tolerance testd was higher in HFDfed mice compared with mice fed the control diet, the control diet $+\mathrm{fNJ}$ and the HFD $+\mathrm{fNJ}$ (Table 3). In HFD-fed mice, glucose intolerance was evident at 30 and $60 \mathrm{~min}$, normalising by $120 \mathrm{~min}$, while insulin intolerance was demonstrated at 0,30 and $60 \mathrm{~min}$, also normalising by $120 \mathrm{~min}$.

Mice fed the HFD + fNJ demonstrated an improved and normalised glucose and insulin tolerance tests curves and the area under the curve when compared with mice fed the HFD (Fig. 1(A); Table 3).

\section{Fermented noni juice improves liver function test in mice fed the high-fat diet}

Liver function was unaffected in mice fed the control diet + fNJ when compared with control diet-fed mice (Table 3). Abnormal liver function test in HFD-fed mice was evident by significantly higher $(P<0.05)$ hepatic aspartate aminotransaminase, alanine aminotransferase and lactate dehydrogenase enzymes when compared with control diet-fed mice. Feeding mice with the HFD + fNJ significantly reduced $(P<0.05)$ these liver enzymes when compared with those fed only the HFD, but remained elevated above that of control diet-fed mice (Table 3). Similarly, serum aspartate aminotransaminase and alanine aminotransferase were significantly reduced $(P<0.05)$ in mice fed the control diet $+\mathrm{fNJ}$ when compared with mice fed the HFD + fNJ (Table 3) and were comparable with those of control diet-fed mice.

\section{Fermented noni juice lowers hepatic forkhead box O gene expression and gluconeogenic genes in mice fed the high-fat diet}

Microarray conducted on liver tissues resulted in a large number of genes altered by feeding of the HFD + fNJ. An independent manuscript is being prepared depicting the global overview of results and categorising significant pathways of metabolic and cellular functions. The primary focus of this manuscript is to investigate the effects of noni

Table 4. Fold change of glucose-metabolising genes in C57BL/6 mice fed the high-fat diet (HFD) and fermented noni juice (fNJ), analysed by the complementary DNA microarray technique

\begin{tabular}{llcccc}
\hline Gene name & Symbol & Control & Control + fNJ & HFD & HFD + fNJ \\
\hline Aldolase 1 & Aldoa & 1.0 & 1.17 & 3.38 & ND \\
Phosphoenolpyruvate carboxykinase & PEPCK $(P c k)$ & 1.0 & 0.55 & 2.45 & 0.1804 \\
Glucose-6-phosphatase & G6Pc & 1.0 & 0.63 & 2.239 & 1.25 \\
Phosphofructokinase & Pfkl & 1.0 & 0.39 & 2.34 & 1.86 \\
Glucokinase & Gck & ND & ND & ND & 2.75 \\
Glyceraldehyde-3-phosphate & Ga3P & ND & ND & 2.78 & 1.28 \\
Forkhead box O1 & FoxO1 & 1.0 & 2.61 & 9.33 & 3.07 \\
\hline
\end{tabular}

ND, not detected. 

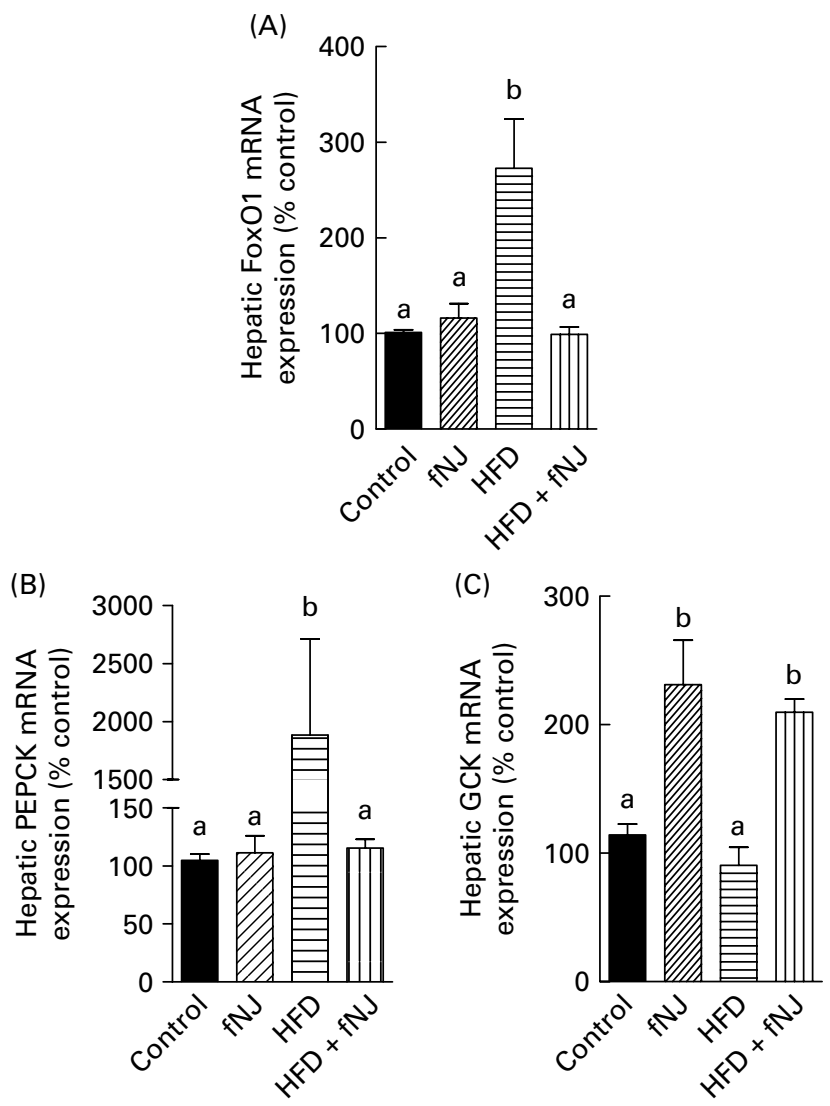

Fig. 2. Effect of fermented noni juice ( $\mathrm{fNJ}$ ) on glucose metabolising genes in high-fat diet (HFD)-fed mice. mRNA expression of (A) hepatic forkhead transcription factor 1 (FoxO1), (B) phosphoenolpyruvate carboxykinase (PEPCK2) and (C) glucokinase (GCK) in mice fed the HFD + fNJ. mRNA expression was quantified by real-time RT-PCR and values are presented as percentage of control values. Values are means, with standard errors represented by vertical bars $(n 4) .{ }^{\text {a,b }}$ Mean values with unlike letters were significantly different $(P<0.05)$.

on hepatic gluconeogenesis. Therefore, selective relevant glucose-metabolising genes have been depicted in Table 4 that were changed by more than $2 \cdot 0$-fold among mice fed the HFD. Fig. 2 demonstrates the percentage change in representative genes as measured by real-time RT-PCR. The HFD significantly increased FoxO1 mRNA expression by more than 170 and $150 \%(P<0.05)$, above that of control diet-fed mice and control diet + fNJ-fed mice, respectively (Fig. 2(A)). Interestingly, the mRNA expression of FoxO-downstream gene, PEPCK2, was significantly increased $(P<0.05)$ by more than $2000 \%$, in HFD-fed mice when compared with control dietfed mice and control diet + fNJ-fed mice (Fig. 2(B)), while the mRNA expression of the G6P gene remained unchanged (data not shown). The mRNA expression of FoxO1 and PEPCK genes were normalised in mice fed the HFD + fNJ (Fig. 2(A) and (B), respectively). In contrast, the mRNA expression of glycolytic gene, GCK, was not significantly altered in HFD-fed mice compared with both the control and control $+\mathrm{fNJ}$ groups, but was significantly elevated $(P<0.05)$ in mice fed the HFD + fNJ by more than $100 \%$ above that of all the other groups (Fig. 2(C)). The mRNA expression of the FoxO1 and PEPCK genes in control diet + fNJ-fed mice were comparable with those of control diet-fed mice (Fig. 2(A) and (B)). In contrast, the control diet $+\mathrm{fNJ}$ diet significantly elevated $G C K$ gene expression when compared with control diet-fed mice $(P<0.05$; Fig. 2(C)).

\section{Fermented noni juice increases phosphorylation of nuclear forkhead box $\mathrm{O}$ in mice fed the high-fat diet}

Regardless of the gene expression, transcriptional activity is also controlled by phosphorylation of the FoxO protein ${ }^{(18,22)}$, resulting in nuclear expulsion and inhibition of downstream target genes. Western blot analysis of hepatic cellular extracts demonstrated that the HFD significantly reduced $(P<0.05)$ the amounts of phosphorylated FoxO1 and increased $(P<0.05)$ the total FoxO1 protein levels when compared with all the other three groups of mice (Fig. 3(A)). Phosphorylation of hepatic FoxO1 proteins was significantly increased in mice fed the HFD + fNJ when compared with mice fed the HFD $(P<0.05)$, but were not different from both control diet-fed groups (Fig. 3(B) and (C)).

\section{Fermented noni juice increases phosphorylation of forkhead box O in HepG2 cells}

To establish that fNJ-associated effects on FoxO1 are not unique to rodents, we tested the effects of 1.5 and $3 \% \mathrm{fNJ}$ on protein phosphorylation and FoxO mRNA expression in human hepatoma cells, HepG2 using a cell-based commercial ELISA and quantitative RT-PCR, respectively. Overall, cells
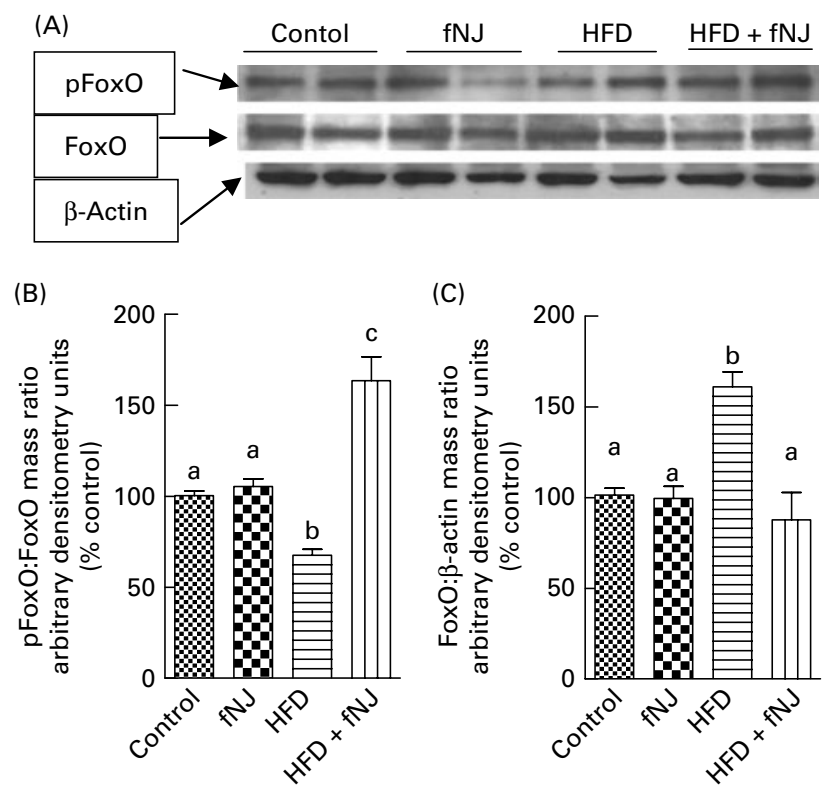

Fig. 3. Effect of fermented noni juice ( $f N J$ ) on protein phosphorylation. (A) $f N J$ lowers tyrosine phosphorylation (pTyr) of hepatic nuclear forkhead transcription factor 1 (FoxO1) in mice fed the high-fat diet (HFD) $+\mathrm{fNJ}$. The bar graphs represent the densitometry scans of (B) pTyr FoxO1 and (C) FoxO1, $95 \mathrm{kDa}$ band intensities. The $42 \mathrm{kDa} \beta$-actin band demonstrates equal amounts of protein loaded on the gel. Data are expressed as a percentage of control values, set at $100 \%$. Values are means, with standard errors represented by vertical bars $(n 6) .{ }^{\text {a,b,c }}$ Mean values with unlike letters were significantly different $(P<0.05)$. pFoxO, phosphorylated FoxO. 


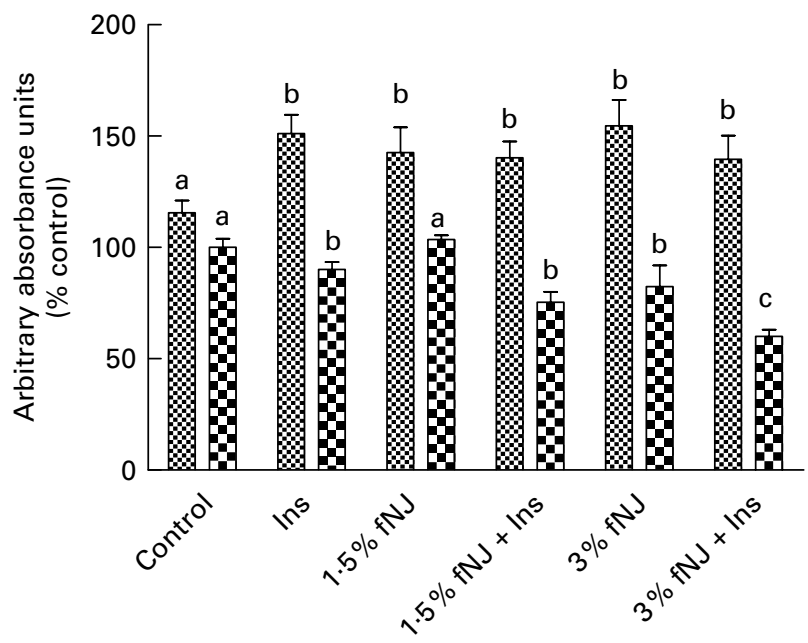

Fig. 4. Effect of fermented noni juice (fNJ) on forkhead transcription factor 1 (FoxO1) proteins in human hepatoma cells, HepG2. fNJ reduced total FoxO1 (B) protein and increased FoxO1 phosphorylation (․․) in HepG2 cells treated in the presence and absence of insulin (positive control for FoxO1 phosphorylation). Three independent experiments were conducted in quadruplets. Values are means, with standard errors represented by vertical bars ( $n$ 12). ${ }^{\mathrm{a}, \mathrm{b}, \mathrm{c}}$ Mean values with unlike letters were significantly different $(P<0.05)$. Con, control; Ins, insulin.

treated with insulin demonstrated a significant increase by $50 \%$ in phosphorylated FoxO1 protein when compared with the control cells (Fig. 4). Treatment with 1.5 or $3 \% \mathrm{fNJ}$ for $24 \mathrm{~h}$ significantly increased FoxO phosphorylation $(P<0.05)$, compared with the control cells but was similar to the cells treated with only insulin $(P<0.05)$ (Fig. 4). Co-treatment of HepG2 cells with $1.5 \%$ fNJ + insulin had no additional benefits since it did not increase FoxO1 phosphorylation or total FoxO above that of the insulin-treated cells. However, addition of $3 \% \mathrm{fNJ}+$ insulin significantly lowered total FoxO proteins compared with all the other groups, but phosphorylated FoxO remained unchanged compared with the other groups except the control group (Fig. 4). In contrast to mice studies, both concentrations of $\mathrm{fNJ}$ had no significant effect on FoxO1 mRNA expression in HepG2 cells (data not shown).

Fermented noni juice inhibits mRNA expression of hepatic gluconeogenic enzymes specifically via forkhead box 01 regulation

The specificity of NJ-associated inhibition of FoxO1 signalling in regulating hepatic gluconeogenesis was determined by the transient knockdown of FoxO1 expression in HepG2 cells using commercial siRNA (Dharmacon, Inc.), according to the manufacturer's instructions. FoxO1 was efficiently knockdown by $80-85 \%(P<0.05)$ after $48 \mathrm{~h}$ of transfection as determined by quantitative RT-PCR (data not shown). The siRNA knockdown of FoxO1 was specific since the siGENOME Non-Targeting siRNA had no effect on FoxO1 mRNA expression determined by quantitative RT-PCR (data not shown). Treatment of HepG2 cells with 1.5 and $3 \% \mathrm{fNJ}$ resulted in a modest but significant $33-40 \%$ reduction of PEPCK gene expression $(P<0 \cdot 05)$, while the cells treated with FoxO1
siRNA, in the presence or absence of $\mathrm{fNJ}$, demonstrated a significant reduction $(P<0.05)$ of PEPCK expression by 55-58\% (Fig. 5(A)). Similarly, both concentrations of $\mathrm{fNJ}$ significantly reduced $(P<0.05)$ G $6 P$ mRNA gene expression in control HepG 2 cells by $50-60 \%$, but the reduction was more than $72 \%$ in cells treated with FoxO siRNA (Fig. 5(B)). Overall, no dose-dependent effects were observed in the fNJ-treated cells.

It was observed that $80-85 \%$ inhibition of FoxO (Fig. 4) resulted in more than 60 and $75 \%$ reduction in PEPCK and G6P mRNA expression, respectively (Fig. 5). However, cells treated with fNJ demonstrated only a 40-50\% reduction in PEPCK and G6P mRNA expression, respectively, which was lower than that observed in FoxO1 siRNA-targeted HepG2 cells. This difference is expected since fNJ reduces FoxO1 protein by $50 \%$ in HepG 2 cells and normalises to control

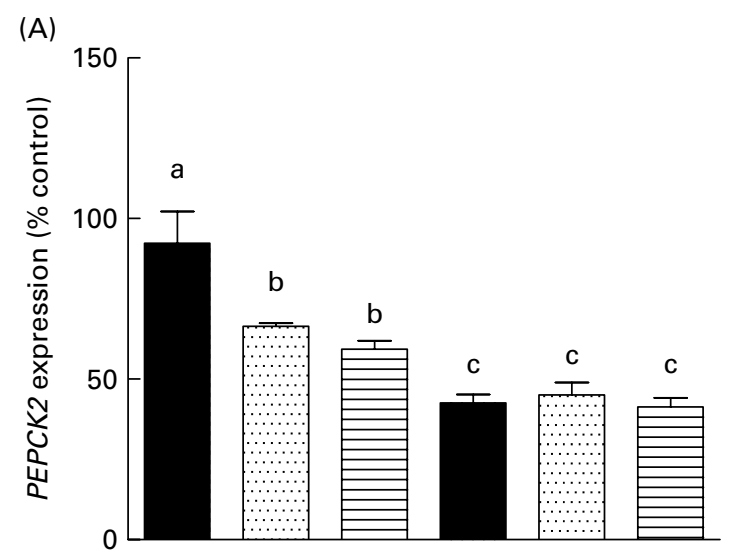

(B)

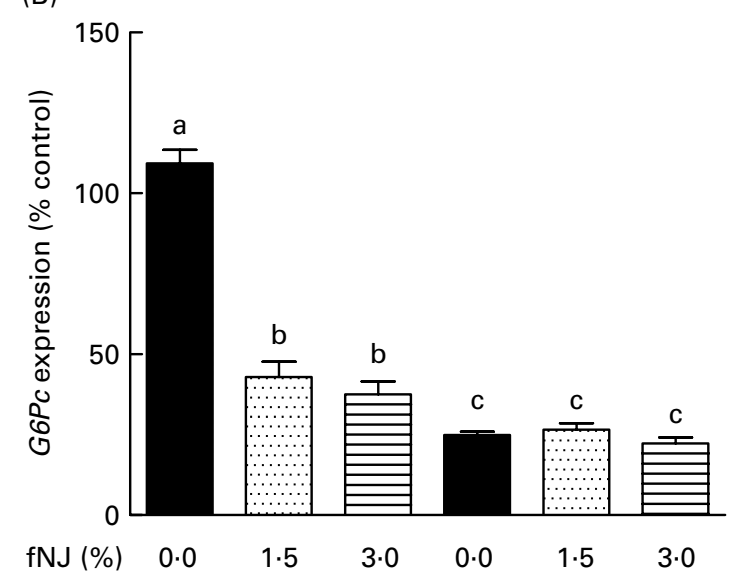

FoxO siRNA $\quad-\quad \begin{array}{lllllllll} & - & - & & + & + & +\end{array}$

Fig. 5. Effect of fermented noni juice ( $\mathrm{fNJ}$ ) on glucose metabolising genes in human hepatoma cells, HepG2. mRNA expression of human (A) phosphoenolpyruvate carboxykinase 2 (PEPCK2) and (B) glucose-6-phosphatase $(G 6 P C)$ genes in HepG2 cells transiently transfected with forkhead transcription factor 1 (FoxO1) small interfering RNA (siRNA). mRNA expression was quantified by real-time RT-PCR and values are presented as percentage of control values. Three independent experiments were conducted in duplicate or triplicate. Values are means, with standard errors represented by vertical bars (n 6-9). ${ }^{\text {a,b,c }}$ Mean values with unlike letters were significantly different $(P<0.05)$. 
levels in HFD-fed mice, and does not completely inhibit FoxO1 (Fig. 4). Our siRNA data indicate that inhibition of PEPCK and G6P expression by fNJ is achieved through FoxO1-dependent and -independent mechanisms. Overall, these data suggest that improvement in glucose metabolism by fNJ is associated with the inhibition of hepatic gluconeogenesis, in part via FoxO1 regulation.

\section{Discussion}

We investigated the long-term effects of fNJ prepared from noni fruits on glucose metabolism in mice fed a HFD containing $58 \%$ fat for 12 weeks, the composition of which reflects Western diets, and is known to induce the metabolic syndrome in $\mathrm{C} 57 \mathrm{BL} / 6$ mice $^{(23)}$. In the present study, the metabolic syndrome phenotype in the HFD-fed mouse model was evident by weight gain, increase in fasting plasma glucose and insulin, as well as glucose and insulin intolerance, which was normalised when the HFD was supplemented with fNJ. We present novel data indicating that fNJ improves hepatic insulin resistance and hyperglycaemia by regulating hepatic transcription factor, FoxO, in mice fed a HFD.

Although earlier studies in HFD-fed mice demonstrated a reduction in blood glucose $e^{(16)}$, to our knowledge, this is the first study to indicate a possible noni juice-associated mechanism involved in lowering blood glucose and improving HFD-associated hepatic insulin resistance. Epidemiological studies have demonstrated that HOMA-IR is a well-defined biomarker to assess insulin resistance and insulin sensitivity $^{(24,25)}$ and a possible indicator of hepatic insulin resistance $^{(26)}$. In the present study, improvement of HOMA-IR, as well as the glucose and insulin tolerance tests, indicates the ability of fNJ to improve hepatic insulin resistance in mice fed the HFD + fNJ. Mechanistic studies are warranted to not only delineate the effects of $\mathrm{fNJ}$ on the hepatic insulin receptor signalling pathway, but also its effects on peripheral insulin resistance.

PEPCK and G6Pc are two important gluconeogenic genes regulated by insulin. Improvement in hepatic gluconeogenesis was evident by a significant reduction in PEPCK mRNA gene expression among mice fed a HFD + fNJ. Besides gluconeogenesis, hepatic glucose utilisation via glycolysis also contributes to maintain plasma glucose levels within physiological limits. Studies in both human subjects and rodents have supported a critical role for GCK in glucose homoeostasis, which is highly expressed in liver and pancreatic $\beta$-cells and is known to regulate hepatic glucose metabolism and insulin secretion $^{(27)}$. GCK catalyses the first step of glycolysis in the liver by converting glucose to G6P. Reduced GCK activity has been linked to abnormal insulin secretion from pancreatic $\beta$-cells and glucose tolerance. Earlier studies have demonstrated that hepatic mRNA expression and activity of GCK were increased in HFD-fed wild-type as well as GCK knockout mice ${ }^{(28)}$. However, we did not observe any changes in the hepatic GCK mRNA content of HFD-fed mice, possibly due to differences in either the type of diet or the sex of mice used. Regardless, our studies demonstrate that fNJ improves glucose metabolism by increasing glycolysis as evident by the significantly increased GCK mRNA expression in the livers of mice fed the HFD $+\mathrm{fNJ}$. Overall, in our studies, the HFD increased gluconeogenesis but had no effect on glycolysis, while fNJ improved both pathways of glucose metabolism. Studies are warranted on additional glycolytic factors such as glycogen metabolism and peripheral glucose utilisation.

In the liver, metabolic adaptations to nutrient overflow are regulated at the level of gene transcription. In the present study, the reduction of PEPCK mRNA gene expression by fNJ was associated, in part, with the regulation of transcription factor, FoxO1, which is an important upstream regulator of key enzymes involved in glucose metabolism (gluconeogenesis, glycolysis, pentose phosphate shunt ${ }^{(16,29)}$. Transcriptional activity of FoxO or FoxO function is governed by posttranscriptional modifications such acetylation, ubiquitination and phosphorylation. Insulin can inhibit the transcriptional regulation of glucose metabolising genes (PEPCK, G6PC and $G C K$ ) by phosphorylating FoxO via the Akt/phosphatidylinositol-3-kinase pathway and subsequently translocating it from the nucleus to the cytoplasm ${ }^{(18,22,30)}$. Transgenic mice, constitutively overexpressing hepatic FoxO1, demonstrate increased fasting glucose levels despite hyperinsulinaemia and reduced glucose tolerance and insulin sensitivity ${ }^{(16)}$. Similarly, in the present study, we observed an increase in FoxO function in HFD-fed mice in the presence of hyperinsulinaemia, which can be an additional contributing factor towards insulin intolerance. In contrast, inhibition of FoxO1 was associated with improved fasting glucose levels in $\mathrm{db} / \mathrm{db}$ diabetic mice ${ }^{(31)}$. Altomonte et al. ${ }^{(31)}$ elegantly demonstrated that mutant FoxO1 vector, FoxO1- $\Delta 256$, interfered with FoxO1 function in the liver by inhibiting the binding of FoxO1 to the promoter of its target genes such as PEPCK and $G 6 P$ and reducing gluconeogenesis.

A recent study has elegantly demonstrated that the Chinese herb berberine simultaneously reduced FoxO mRNA expression that correlates with the demonstrated reduction in nuclear and cytoplasmic phosphorylated FoxO and total FoxO in diabetic mice treated with berberine when compared with diabetic mice ${ }^{(32)}$. Although we did not compare the nuclear and cytoplasmic distribution of phospho- and totalFoxO protein levels, the fact that fNJ reduces or normalises FoxO mRNA expression and the protein levels indicates a reduction in FoxO function. The regulation of glucose metabolism by the fNJ-associated inhibition of FoxO1 was further confirmed through the transient knockdown of FoxO1 in HepG2 cells, which demonstrated a concomitant reduction of PEPCK and G6PC, similar to that observed in our mice studies. Overall, the present results support the concept that fNJ regulates glucose metabolism by suppressing FoxO function to regulate genes involved in promoting hepatic gluconeogenic and glycolytic enzymes as well as liver TAG and plasma glucose in mice fed the HFD + fNJ. It is possible that fNJ regulates FoxO1 mRNA levels by inhibiting its upstream regulators such as histone deacetylase 1 in the liver ${ }^{(33)}$.

Similar to the present findings, previous studies have demonstrated that fNJ attenuated hyperglycaemia in streptozotocin-induced diabetic rats receiving $\mathrm{fNJ}$ in drinking-water for $10 \mathrm{~d}(100 \mathrm{ml} / \mathrm{kg} \text { body weight })^{(11)}$. A study by Horsfall et al. ${ }^{(13)}$ 
demonstrated the synergistic effect of $\mathrm{fNJ}$ on insulin to improve alloxan-induced hyperglycaemia in diabetic rats after 4 weeks of treatment. Furthermore, studies by Soon et $a l .{ }^{(12)}$ and Kamiya et $a .^{(10)}$ demonstrated that organic solvent extract from the roots of $M$. officinalis and $M$. citrifolia (noni) reduced fasting serum glucose in streptozotocininduced diabetic animals, $3 \mathrm{~h}$ after administration. Interestingly, Soon et al. ${ }^{(12)}$ also observed that noni root extract increased fasting glucose levels in control rats ${ }^{(12)}$, which is in contrast to the present study, where we do not observe any hyperglycaemic effects of fNJ when fed to control mice. The differences could be due to the different noni extracts (root extract $v$. fruit juice) and experimental conditions in the two studies. However, none of the previous studies delineated the mechanisms by which fNJ restored glucose homeostasis ${ }^{(10-13)}$.

Our data also demonstrate that fNJ reduced weight gain in mice fed the HFD + fNJ when compared with control dietfed mice. Previous studies were unable to demonstrate any effect of whole NJ on body weight or lipid metabolism possibly due to the shorter duration of the $\mathrm{NJ}$ treatment ranging from few hours to 4 weeks after induction of diabetes, or differences in methods of preparation or differences in parts of noni plant used in these experiments ${ }^{(10-13)}$. In contrast, Mandukhail et al. ${ }^{(34)}$ demonstrated that commercial, $70 \%$ aqueous ethanolic extracts of noni fruit, leaf and roots were able to reduce hyperlipidaemia, fasting glucose and body-weight gain in rats fed a HFD.

NJ contains numerous chemicals including saponins, triterpenes, flavanoids, coumarins and iridoids ${ }^{(35-37)}$. Similarly, besides scopoletin, we were able to detect quercetin as well as anthocyanin, cyanidin-3-O-rutinoside, in methanolic extracts of fNJ using HPLC (data not shown). Both, quercetin and anthocyanin are known to improve hyperglycaemia in animal models ${ }^{(38,39)}$. Interestingly, quercetin has recently been demonstrated to inhibit stress via FoxO regulation in Caenorhabditis elegans ${ }^{(38,40)}$. It is therefore possible that anti-diabetic properties of fNJ in our studies are in part associated with flavanoids such as quercetin and anthocyanin. Currently, there are no established doses for human consumption of $\mathrm{NJ}$, which is a mixture of anthraquinones, organic acids, xeronine, flavanoids, $\mathrm{Fe}, \mathrm{Ca}, \mathrm{K}$ as well as vitamins, such as $\beta$-carotene, niacin, riboflavin and thiamin. Future studies are warranted to determine physiologically relevant doses of fNJ and to delineate the active components of noni that regulate glucose and lipid metabolism. Furthermore, exact combination of compounds in $\mathrm{NJ}$ requires further elucidation to determine its beneficial properties.

\section{Conclusions}

Overall, the present study indicates that fNJ supplementation improves plasma glucose levels in HFD-fed mice by modulating hepatic gene expression of gluconeogenic and glycolytic enzymes via FoxO1 phosphorylation. Diabetes represents one of the world's greatest health care challenges not only due to the rising incidence, but also the ever-increasing health care costs. Although fNJ can form a complementary treatment initially, complete characterisation of the active compounds may lead to novel treatments for diabetes. Advances in identifying alternative and affordable sources of treatment options, such as noni, can help to reduce health disparities in culturally sensitive populations as well as to reduce health care costs and offer a low-cost alternative specifically in the developing countries where general allopathic medicine is beyond the financial reach of low-income populations.

\section{Acknowledgements}

This study was supported partly by grants from the USDA-CREES (2004-34135-15182) and the National Center for Complementary and Alternative Medicine (R21AT003719), the National Center for Minority Health Disparity (P20MD000173), and Research Centers in Minority Institutions Program, National Center for Research Resources (G12RR003061), National Institutes of Health. We thank Dr Will McClatchey (Professor, Department of Botany, University of Hawaii) for identifying the noni specimens, voucher preparation and deposition into the herbarium. P. V. N. conceived and designed the study as well as analysed and interpreted the data, and wrote the manuscript. A. N., P. O. E., L. M. J. and E. V. performed the experiments for data acquisition. V. R. N. was involved in the data analysis and critically revising the manuscript for important intellectual content. P. V. N. has primary responsibility for the final content. Partial data were presented as a poster at the April 2010 ASBMB Annual meeting. All authors read and approved the final version of the manuscript. All the authors declare that they do not have any competing interests.

\section{References}

1. McClatchey W (2002) From Polynesian healers to health food stores: changing perspectives of Morinda citrifolia (Rubiaceae). Integr Cancer Ther 1, 110-120.

2. Pawlus AD \& Kinghorn DA (2007) Review of the ethnobotany, chemistry, biological activity and safety of the botanical dietary supplement Morinda citrifolia (noni). J Pharm Pharmacol 59, 1587-1609.

3. Noni Biotech International (2011) All About Noni. http:// nonimaui.com/all.about.noni

4. Akihisa T, Matsumoto K, Tokuda H, et al. (2007) Anti-inflammatory and potential cancer chemopreventive constituents of the fruits of Morinda citrifolia (Noni). J Nat Prod 70, 754-757.

5. Furusawa E, Hirazumi A, Story S, et al. (2003) Antitumour potential of a polysaccharide-rich substance from the fruit juice of Morinda citrifolia (Noni) on sarcoma 180 ascites tumour in mice. Phytother Res 17, 1158-1164.

6. Li J, Stickel SL, Bouton-Verville H, et al. (2008) Fermented noni exudate (fNE): a mediator between immune system and anti-tumor activity. Oncol Rep 20, 1505-1509.

7. Wang MY, Anderson G \& Nowicki D (2002) Preventive effect of Morinda citrifolia (Noni) at the initiation stage of mammary breast cancer induced by 7,12-dimethylbenz(a)anthracen (DMBA) in female Sprague-Dawley rats. In The Proceedings of the Frontiers in Cancer Prevention Research, AACR, Boston, MA, USA, 17 October 2002. 
8. Wang MY \& Su C (2001) Cancer preventive effect of Morinda citrifolia (Noni). Ann N Y Acad Sci 952, 161-168.

9. Zhang X, Li J, Wong DK, et al. (2009) Fermented noni exudate-treated dendritic cells directly stimulate B lymphocyte proliferation and differentiation. Oncol Rep 21, 1147-1152.

10. Kamiya K, Hamabe W, Harada S, et al. (2008) Chemical constituents of Morinda citrifolia roots exhibit hypoglycemic effects in streptozotocin-induced diabetic mice. Biol Pharm Bull 31, 935-938.

11. Nayak BS, Isitor GN, Maxwell A, et al. (2007) Wound-healing activity of Morinda citrifolia fruit juice on diabetes-induced rats. J Wound Care 16, 83-86.

12. Soon YY \& Tan BK (2002) Evaluation of the hypoglycemic and anti-oxidant activities of Morinda officinalis in streptozotocin-induced diabetic rats. Singapore Med J 43, 77-85.

13. Horsfall AU, Olabiyi O, Aiyegbusi A, et al. (2008) Morinda citrifolia fruit juice augments insulin action in SpragueDawley rats with experimentally induced diabetes. Nig Q J Hosp Med 18, 162-165.

14. Matsumoto M, Han S, Kitamura T, et al. (2006) Dual role of transcription factor FoxO1 in controlling hepatic insulin sensitivity and lipid metabolism. J Clin Invest 116, 2464-2472.

15. Matsumoto M, Pocai A, Rossetti L, et al. (2007) Impaired regulation of hepatic glucose production in mice lacking the forkhead transcription factor Foxo1 in liver. Cell Metab 6, 208-216.

16. Zhang W, Patil S, Chauhan B, et al. (2006) FoxO1 regulates multiple metabolic pathways in the liver: effects on gluconeogenic, glycolytic, and lipogenic gene expression. J Biol Chem 281, 10105-10117.

17. van der Heide LP, Hoekman MF \& Smidt MP (2004) The ins and outs of FoxO shuttling: mechanisms of FoxO translocation and transcriptional regulation. Biochem J 380, 297-309.

18. Aoyama H, Daitoku H \& Fukamizu A (2006) Nutrient control of phosphorylation and translocation of Foxo1 in C57BL/6 and $\mathrm{db} / \mathrm{db}$ mice. Int J Mol Med 18, 433-439.

19. Nerurkar PV, Lee YK, Motosue M, et al. (2008) Momordica charantia (bitter melon) reduces plasma apolipoprotein B-100 and increases hepatic insulin receptor substrate and phosphoinositide-3 kinase interactions. Br J Nutr $\mathbf{1 0 0}$, 751-759

20. Nerurkar PV, Johns LM, Buesa LM, et al. (2011) Momordica charantia (bitter melon) attenuates high-fat diet-associated oxidative stress and neuroinflammation. J Neuroinflammation $\mathbf{8}, 64$.

21. Snee LS, Nerurkar VR, Dooley DA, et al. (2011) Strategies to improve palatability and increase consumption intentions for Momordica charantia (bitter melon): a vegetable commonly used for diabetes management. Nutr J 10, 78.

22. Vogt PK, Jiang H \& Aoki M (2005) Triple layer control: phosphorylation, acetylation and ubiquitination of FOXO proteins. Cell Cycle 4, 908-913.

23. Gallou-Kabani C, Vige A, Gross M-S, et al. (2007) C57BL/6 and $\mathrm{A} / \mathrm{J}$ mice fed a high-fat diet delineate components of metabolic syndrome. Obesity 15, 1996-2005.

24. Haffner SM, Miettinen H \& Stern MP (1997) The homeostasis model in the San Antonio Heart Study. Diabetes Care 20, $1087-1092$.

25. Seo K, Choi M-S, Jung UJ, et al. (2008) Effect of curcumin supplementation on blood glucose, plasma insulin, and glucose homeostasis related enzyme activities in diabetic db/db mice. Mol Nutr Food Res 52, 995-1004.

26. Bonora E, Targher G, Alberiche M, et al. (2000) Homeostasis model assessment closely mirror the glucose clamp technique in the assessment of insulin sensitivity. Diabetes Care 23, 57-63.

27. Leighton B, Atkinson A \& Coghlan MP (2005) Small molecule glucokinase activators as novel anti-diabetic agents. Biochem Soc Trans 33, 371-374.

28. Gorman T, Hope DCD, Brownlie R, et al. (2008) Effect of high-fat diet on glucose homeostasis and gene expression in glucokinase knockout mice. Diabetes Obes Metab 10, $885-897$.

29. Frescas D, Valenti L \& Accili D (2005) Nuclear trapping of the forkhead transcription factor FoxO1 via Sirt-dependent deacetylation promotes expression of glucogenetic genes. $J$ Biol Chem 280, 20589-20595.

30. Ganjam GK, Dimova EY, Unterman TG, et al. (2009) FoxO1 and HNF-4 are involved in regulation of hepatic glucokinase gene expression by resveratrol. J Biol Chem 284, 30783-30797.

31. Altomonte J, Richter A, Harbaran S, et al. (2003) Inhibition of Foxo1 function is associated with improved fasting glycemia in diabetic mice. Am J Physiol Endocrinol Metab 285, E718-E728.

32. Xia X, Yan J, Shen Y, et al. (2011) Berberine improves glucose metabolism in diabetic rats by inhibition of hepatic gluconeogenesis. PLoS One 6, e16556.

33. Oiso H, Furukawa N, Suefuji M, et al. (2011) The role of class I histone deacetylase (HDAC) on gluconeogeneis in liver. Biochem Biophys Res Commun 404, 166-172.

34. Mandukhail SU, Aziz N \& Gilani AH (2010) Studies on antidyslipidemic effects of Morinda citrifolia (Noni) fruit, leaves and root extracts. Lipids Health Dis 9, 88.

35. Nayak BS, Marshall JR, Isitor G, et al. (2011) Hypoglycemic and hepatoprotective activity of fermented fruit juice of Morinda citrifolia (Noni) in diabetic rats. Evid Based Complement Alternat Med 2011, 875293.

36. Dussossoy E, Brat P, Bony E, et al. (2010) Characterization, anti-oxidative and anti-inflammatory effects of Costa Rican noni juice (Morinda citrifolia L.). J Ethnopharmacol 133, 108-115.

37. Potterat O \& Hamburger M (2007) Morinda citrifolia (Noni) fruit - phytochemistry, pharmacology, safety. Planta Med 73, 191-199.

38. Kampkotter A, Nkwonkam CG, Zurawski RF, et al. (2007) Investigations of protective effects of the flavonoids quercetin and rutin on stress resistance in the model organism Caenorhabditis elegans. Toxicology 234 , 113-123.

39. Takikawa M, Inoue S, Horio F, et al. (2010) Dietary anthocyanin-rich bilberry extract ameliorates hyperglycemia and insulin sensitivity via activation of AMP-activated protein kinase in diabetic mice. J Nutr 140, 527-533.

40. Kampkotter A, Timpel C, Zurawski RF, et al. (2008) Increase of stress resistance and lifespan of Caenorhabditis elegans by quercetin. Comp Biochem Physiol B Biochem Mol Biol 149, 314-323. 